\title{
Six Sigma and organizational ambidexterity: a systematic review and conceptual framework
}

\author{
Paper published in \\ International Journal of Lean Six Sigma
}

Full citation to this publication:

Alcaide Muñoz, C. and Gutiérrez Gutiérrez, L.J. (2017): "Six Sigma and organizational ambidexterity: a systematic review and conceptual framework". International Journal of Lean Six Sigma. Vol.8, n.4, pp. 436-456. "Highly Commended paper 2017" Emerald Publishing Group.

https://doi.org/10.1108/IJLSS-08-2016-0040

Thank you for your interest in this publication. 


\title{
Six Sigma and organisational ambidexterity: a systematic review and conceptual framework
}

\author{
Cristina Alcaide-Muñoz \\ Public University of Navarre, Pamplona, Spain \\ Leopoldo J. Gutierrez-Gutierrez \\ University of Granada, Granada, Spain
}

\begin{abstract}
Purpose - The aim of this paper is to analyse the relationship between Six Sigma methodology and organisational ambidexterity (exploitation and exploration orientations). For this purpose, this study describes how Six Sigma practices may enhance both orientations simultaneously, contributing to organisational ambidexterity and performance improvements.
\end{abstract}

Design/methodology/approach - A systematic literature review was adopted as the research methodology. The authors analysed 512 publications in Social Science Citation Index (SSCI) journals in fields such as management, business, operation research management science, planning development, behavioural sciences, interdisciplinary social sciences and applied psychology from 1987 to 2016, as the first development and adoption of Six Sigma was in 1987 by Motorola.

Findings - This analysis describes how Six Sigma emphasises not only useful practices for exploitation orientation, such as customer input, design for manufacturability or improvement and control of processes, but also explorative practices, such as discovery, novelty or innovation. Consequently, an adequate combination of all these practices may enhance organisational ambidexterity and organisational success.

Research limitations/implications - This study relies exclusively on previously published literature that fulfilled the selection criteria described in the search methodology. Further empirical research is necessary to test the propositions included in this paper.

Originality/value - This study provides new insights into the non-existent literature about Six Sigma and organisational ambidexterity as well as to the scarce literature about quality management and ambidexterity. Propositions on how Six Sigma practices benefit organisational ambidexterity are also suggested.

Paper type: Literature review/conceptual paper.

\section{Introduction}


Academics and practitioners advocate that Six Sigma comprises the best quality practices to address business issues such as customer focus, process innovation and quality improvement (Rowlands, 2003; Hoerl et al, 2010; Choi, 2012). However, there are mixed results concerning its positive impact on organisational performance, and the failure rate of Six Sigma implementation is approximately 60\% (Gupta, 2005). On one hand, organisations such as 3M's Dental Division (Baldrige Award winner), Ford, General Electric, AlliedSignal, Honeywell and American Express have adopted Six Sigma and claimed that it has transformed their organisation, enhancing their business performance (Hahn et al, 2000; Tjahjono et al, 2010; Swink \& Jacobs, 2012; Reosekar et al, 2014). On the other hand, organisations such as Motorola, Ericsson and Samsung did not have good results. Although they saved billions with the help of Six Sigma in the early years, its adoption failed to improve their performance in the long run (Clifford, 2001; Barney, 2002; Folaron, 2003; Richardson, 2007; Chakravorty, 2009; Chandrasekaran et al, 2012).

To advance research about Six Sigma benefits, many authors have devoted their efforts to describing its effects on organisations in-depth. Their studies have analysed the relationship between Six Sigma and competencies such as flexibility, differentiation, fast delivery, zero defects, rapid design or redesign, cost reduction, innovation, knowledge creation and so forth (Foster, 2007; Pepper et al, 2010; Easton \& Rosenzweig, 2012; Sin et al, 2015; Arumugam et al, 2016; Gutierrez-Gutierrez, 2016).

At present, one of the most important organisational competencies is ambidexterity (Gibson \& Birkinshaw, 2004; Moreno Luzon \& Valls Pasola, 2011; Volery et al, 2015; Zhang et al, 2016), which refers to an organisation's ability to develop both exploitative and explorative orientations (March, 1991). Exploitation orientation comprises activities such as the improvement and control of stable and familiar processes (mechanistic orientation), and exploration orientation is related to innovation and creative activities in order to explore new alternatives (organic orientation) (Zhang et al, 2012). Scholars have pointed out the need to combine both exploitation and exploration orientations (organisational ambidexterity), as promoting just one of them is not enough to assist organisations competing in a hypercompetitive and dynamic environment (March, 1991; Gupta et al, 2006; Im \& Rai, 2008; Kristal, 2010; Chandrasekaran et al, 2012; Salvador et al, 2014). For instance, Lloyds TSB Bank Plc lost $60 \%$ of its market value between 1998 and 2003, because it paid attention only to the control and refinement 
process (exploitation orientation), neglecting changing customer needs, or to the morale of the workforce (exploration orientation) (Birkinshaw \& Gibson, 2004). In contrast, organisations such as Finland's Nokia Corp. and GlaxoSmithKline Plc are excellent examples to show how ambidexterity may help organisations achieve sustainable competitive advantages. Yet, due to scarce available resources, finding an adequate combination of both orientations becomes a challenge for organisations (Gibson \& Birkinshaw, 2004; O’Reilly \& Tushman, 2008; Kortman, 2015).

Schroeder et al. (2008) suggested for future research that Six Sigma might promote exploration and exploitation orientations within organisations, but no study, to date, has developed and analysed this idea. In this regard, the authors have carried out a comprehensive effort to deeply examine and support Schroeder et al's (2008) idea for developing a conceptual model. Because of its particular and comprehensive structure, the authors believe that Six Sigma not only fosters activities to explore both external and internal problems and control process improvement activities (exploitation orientation), but also build better and innovative ways for designing and developing projects, processes and procedures (exploration orientation).

Our study provides new insight to the non-existent literature about Six Sigma and ambidexterity as well as to the scarce literature about QM and ambidexterity. Our model/framework highlights the usefulness and extends the scope of Six Sigma to promote ambidexterity within organisations. Six Sigma goes beyond a simple quality management method as it involves both customers and employees in order to improve and, in turn, redesign processes, procedures, products or services. Incomplete Six Sigma implementation focuses exclusively on, for example, improvement processes, products or services -exploitation orientation. Nevertheless, a complete Six Sigma implementation would develop all its possibilities, combining both exploration and exploitation orientations. In brief, our study aims to analyse the relationship between Six Sigma methodology and organisational ambidexterity, analysing how its practices may foster exploration and exploitation orientations simultaneously within organisations.

To develop this study, a deep and comprehensive literature review in well recognised international journals was developed. The selection of research studies is more systematic, explicit and rigorous than the traditional narrative review, consisting of 
three phases: research protocol, selection of database searching process and evaluation and selection of articles.

The organization of this paper is as follows. Firstly, the authors describe methodology employed. The authors then carry out a deep understanding of Six Sigma and its three specific practices (role structure, improvement procedures and metrics) as well as exploration and exploitation orientations (organizational ambidexterity). In the third section, the authors develop some propositions with justifications that relate Six Sigma and organizational ambidexterity. Finally, conclusions and future research lines are included.

\section{Methodology}

The authors carried out a comprehensive search for the study. The authors adopted a systematic literature review as the research methodology. It differs from the traditional narrative reviews by being more systematic and explicit in the selection of the research, and by developing rigorous and reproducible methods of evaluation (Denyer \& Tranfields, 2009). This type of literature review follows three phases: research protocol, selection of database searching process and evaluation and selection of articles (refer to fig. 1).

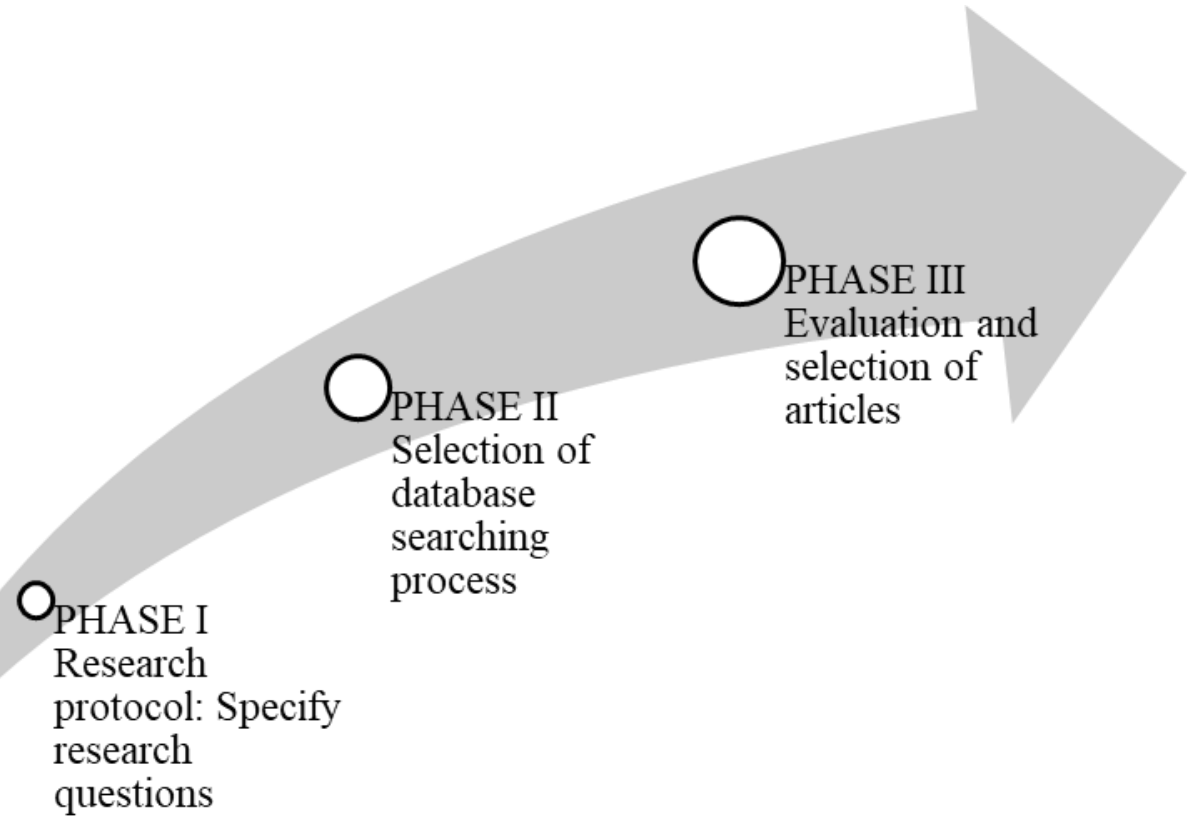

Source: Own elaboration.

Figure 1. The three phases of our literature review 


\subsection{Research protocol}

This phase defines the scope of the research, so the review protocol was developed around the following research questions:

a) Is Six Sigma positively related to exploitation orientation?

b) Is Six Sigma positively related to exploration orientation?

c) Can Six Sigma help organisations combine both orientations (organisational ambidexterity)?

d) If so, which Six Sigma practices foster both exploration and exploitation orientations within organisations and their combination (organisational ambidexterity)?

e) To what extent does Six Sigma foster organisational ambidexterity?

The authors analysed both qualitative and quantitative studies related to QM and organisational ambidexterity to answer the research questions.

\subsection{Selection of database searching process}

The selection of a database searching process was done in three stages: the search of sources, the selection of database and keywords and the inclusion-exclusion criteria. The first of these stages is the search of sources. The authors focused on analysing publications in Social Science Citation Index (SSCI) journals in fields such as management, business, operation research management science, planning development, behavioural sciences, interdisciplinary social sciences and applied psychology, because it constitutes a resource used by academics as a source both to acquire and disseminate knowledge (Nord \& Nord, 1995) as well as an indicator of scientific productivity (Legge \& Devore, 1987). Additionally, the importance of the book as a vehicle of communication has been weakened over time (Ullah et al, 2008), and it is being replaced by the use of online sources (Kriebel \& Lapham, 2008).

Moreover, the authors excluded an analysis of editorials, brief communications, letters to the editor, symposiums, articles of a professional nature and book reviews because, according to Alcaide and Rodríguez (2015), they offer a limited view of the subject. Nevertheless, in the course of our research, the authors took into account articles that were included in special issues of journals because they reflect a great interest in the 
study of any issue and because they need to be examined further (Rodríguez et al, 2010).

In the second stage, the selection of database and keywords, the authors collected journals from the SSCI compiled by the Institute for Scientific Information (ISI) on the Web of Science (electronic database). The main reason for this is that the ISI citation databases 'collectively index more than 8,000 high quality, peer-reviewed journals cover-to-cover, providing users with complete bibliographic data, full-length author abstracts, and cited reference from the world's most influential research' (Newbert, 2007); that is, it is a web-based user interface of ISI's citation databases, which assures high quality and comprehensive search results.

The keywords selected were 'Six Sigma', 'quality management', 'quality improvement', 'exploration and exploitation learning' and 'ambidexterity' and each selected article contains at least one of these words in the title or abstract.

The third stage is based on the development of inclusion-exclusion criteria for articles. The search was done for 1987 to 2016, because in 1987 Motorola started adopting Six Sigma (Harry, M.J., 1998). This search resulted in 8,273 publications. As noted above, the authors searched fields such as management, business, operation research management science, planning development, behavioural sciences, interdisciplinary social sciences and applied psychology, where most studies on Six Sigma and organisational ambidexterity are published. Furthermore, the authors are not interested in the technical process of Six Sigma, but in its management, implementation, adoption and effects over organizations.

Finally, after refining the search, the authors obtained 1,532 publications of which only $512(33.42 \%)$ were read entirely, as their objectives related to Six Sigma implementation, exploration and exploitation orientations and organisational ambidexterity (refer to table 1). The remaining articles were either not written in English or Spanish, or not directly related to fields mentioned above.

Table 1

Keywords used and numbers of papers extracted through overall search. 
Six Sigma

DMAIC

DMADV

Quality Management and Exploration and

9 (out of a total of 18) papers

Exploitation Learning

Quality Improvement and Exploration and

Exploitation Learning

Exploration and Exploitation Learning

Ambidexterity
191 (out of a total of 382) papers

71 (out of a total of 173) papers

4 (out of a total of 18) papers

2 (out of a total of 5) papers

121 (out of a total of 580) papers

114 (out of a total of 356) papers

Total

\subsection{Evaluation and selection of articles}

The last phase was to review each article determined previously. In order to carry this out, the authors analysed the title, keywords and abstract (Lan \& Anders, 2000; Hartley \& Kostoff, 2003) as well as the introduction of each article to identify its purpose. Once the relevant articles to our research were identified, the authors read them thoughtfully.

\section{Literature review}

\subsection{Definition and practices of Six Sigma}

Linderman et al (2003) defined Six Sigma as 'an organised and systematic method for strategic process improvement and new product and service development that relies on statistical methods and the scientific method to make dramatic reduction in customer defined defect rates' (Linderman et al, 2003, p. 194). Thus, Six Sigma gives priority to preventive measures to remove the root cause of the defects instead of searching for defects after they happen (Rowlands, 2003). Additionally, Six Sigma helps decisionmakers create new ideas and systematic solutions for problems in the globalised marketplace (Aggogeri \& Gentili, 2008). In fact, it is generally accepted that the way 
Six Sigma is practiced represents a new organisational, structural approach to improvement (He et al, 2015).

To reach these goals, Six Sigma has three key practices that make it different from traditional quality methods such as ISO 9000, Total Quality Management (TQM), European Foundation for Quality Management (EFQM) Excellent model and so on ( $\mathrm{Zu}$ et al, 2008; Schroeder et al, 2008). They are the following:

a) Six Sigma structured improvement procedure: Six Sigma consists of different approaches. One of them is a structured approach to manage improvement activities, known as the Define-Measure-Analyse-Improve-Control (DMAIC) cycle. This cycle is defined by Schroeder et al. (2008, p. 542) as 'a routine for chain established routines or for inventing new routines, and so solving different problems and improve process (via standards quality tools and techniques such as cause-effects charts and statistical process control), besides it focuses on finding the root cause of the problem by its systematic use'. Another approach is Define-Measure-Analyse-Design-Verify (DMADV), also known as Design For Six Sigma (DFSS), which is used to design and redesign processes, procedures, projects, products and services from the ground up; thus, it requires useful information related to customers' expectations as well as the external and internal organisational environment (Shahin, 2008; Azis \& Osada, 2010; Gremyr \& Fouquet, 2012).

b) Six Sigma metrics: Six Sigma develops several quantitative and statistical metrics such as defects per million opportunities (DPMO), rolled throughput yield (RTY), customer satisfaction score (CSAT score), critical-to-quality metrics (CTQ), defects and 10x improvement measures in order to set improvement goals (Breyfogle et al, 2001; Linderman et al, 2003; Nikolac et al, 2015).

c) Six Sigma role structure: Six Sigma uses a group of improvement specialists, referred to as Champions, Master Black Belts, Black Belts and Green Belts (Henderson \& Evans, 2000; Linderman et al, 2003), who are highly qualified and keep their quality management skills up to date, as they usually receive intensive differentiated training focused on improving their knowledge and skills in statistical methods, project management, process design, problem-solving techniques, leadership and other managerial issues (Barney, 2002; Linderman et al, 2003; Gowen \& Tallon, 2005; Aggogeri \& Gentili, 2008; Antony \& Karaminas, 2016). Furthermore, they take a different level of roles and are accountable for leading the continuous improvement 
efforts to ensure that the tactical tasks match the overall business strategy (Sinha \& Van de Ven, 2005). On the other hand, employees involved in Six Sigma implementation are usually rewarded, increasing employee motivation and satisfaction (Buch \& Rivers, 2001). In fact, employees normally see Six Sigma as an avenue to higher pay through better performance appraisals and eventual promotions (Kim, 2006).

\subsection{Exploration and exploitation orientation: Organisational ambidexterity}

The distinction between exploitation and exploration orientations has been highlighted in a wide range of management literature. As long ago as 1991, March identified exploration and exploitation orientations as two fundamentally different learning activities. Because of scarce resources, organisations must divide their attention between them. March (1991) defined exploratory learning as any organisational practice that fosters search, discovery, novelty and innovation; and exploitative learning as refinement, routinisation, production and implementation of knowledge. Likewise, the authors suggest that exploitation orientation comprises activities such as refinement, choice, production, efficiency, learning and explicit knowledge creation, and exploration orientation as those activities such as search, discovery, experimentation, variation, innovation, learning and tacit knowledge creation.

The emerging discussion on whether to find a balance or to combine these two orientations has been observed in many contexts and disciplines such as organisational theory networks, technological innovation, organisational adaptation, strategic management, inter-organisational relationships and organisation design (Gupta et al., 2006; He \& Wong, 2004; Yang et al, 2013; Eriksson, 2013). Organisations that only promote exploitation orientation may enhance short-term performance; but this may, in turn, lead to a non-response to environmental changes (Leonard-Barton, 1992; Ahuja \& Lampert, 2001; Lavie et al, 2010). However, if organisations focus on exploration orientation they may enhance their ability to renew their knowledge and learning, although they may be trapped in an endless cycle of searching for and collecting too much information (Volberda \& Lewin, 2003). In this sense, Levinthal and March (1993, p. 105) claimed that long-term survival depend on an organisation's ability to 'engage in enough exploitation to ensure the organization's current viability and to engage in enough exploration to ensure future viability', which is currently known as ambidexterity. O'Connor and DeMartino (2006, p. 493) defined ambidexterity as, 'the 
ability of business unit managers to simultaneously advance radical innovation initiatives while conducting daily operational functions'. In other words, it refers to an organisation's ability to run both orientations at the same time.

Both advocates and critics agree that the development of ambidexterity can have a positive influence over business performance and its competitive position in the marketplace, regardless of whether an organisation promotes the balance or combination of both orientations (Gibson \& Birkinshaw, 2004; Gupta et al, 2006; Li et al, 2008; Raisch et al, 2009; Lavie et al, 2010; Salvador et al, 2014).

\section{Research model: Relationship between Six Sigma, and exploitation and exploration orientation}

As mentioned above, exploration and exploitation orientations, as well as their combination, organisational ambidexterity, have been examined in many contexts. Among these contexts, QM and ambidexterity have recently emerged as a new research line. For instance, Zhang et al. (2012) developed a framework where quality practices ensure the monitoring of stable process and the consistency and efficiency of outcomes and foster creativity in organisations. Two years later, Zhang et al. (2014) empirically explored their proposals to best understand the implication of both quality management exploitation (QEI) and quality management exploration (QER) considering different environmental markets (competitive, turbulent, stable and innovative). Their findings showed that there is a performance difference in the two sets of QM practices, taking into account the level of competition and rate of product change. QER has more implications in competitive, innovative and turbulent environments, but QEI operates more efficiently in stable environments; both of them, however, have an important implication in the four types of environments.

Prior to the preceding studies, Schroeder et al. (2008) pointed out that Six Sigma could be viewed as a way to achieve organisational ambidexterity in order to help organisations achieve a successful business performance. Nevertheless, no research to date has carried out a thorough study to support Schroeder's statements in 2008, that is, to show how Six Sigma structure may promote ambidexterity within organisations. Consequently, our purpose is to deeply analyse and relate Six Sigma methodology to 
ambidextrous organisations in order to achieve a sustainable competitive advantage by means of a conceptual study.

For this purpose, next, the authors analyse how each specific practice of Six Sigma (structured improvement process, focus on metrics and role structure) ( $\mathrm{Zu}$ et al, 2008; Schroeder et al, 2008) is connected with exploitation and exploration orientations, and consequently, with organisational ambidexterity.

\subsection{Six Sigma and exploitation orientation}

Six Sigma develops a structured approach to manage improvement activities, known as the Define-Measure-Analyse-Improve-Control (DMAIC) method (Linderman et al, 2003). DMAIC provides a metaroutine, which is followed by organisational members to improve processes and ensure an adequate search for solutions. In other words, DMAIC is a mechanical process not only to solve problems, but also to improve, adopt and control processes and procedures (exploitation orientation). In addition, the involvement of workers in each part of the Six Sigma practices enables the collection, storage and sharing of information, which leads to improve and monitor procedures and processes more efficiently (Arumugam et al, 2013; Nair et al, 2011; McAdam et al, 2014; Gutierrez-Gutierrez et al, 2016a). Therefore, it promotes and facilitates interaction between organisational members providing standards, systems and roadmaps, which help them solve different issues and perform their tasks within organisations (exploitation orientation) in addition to enhancing procedures, processes, products and services (refer to fig. 1). For example, Prashar (2016) carried out a study case to identify defects and to guide process improvement in energy meter-reading in the context of public utilities. The author stratified the DMAIC approach, showing different tools such as an affinity diagram, perception analysis, a cause and effect diagram, Gemba investigation and so forth, to improve and measure processes and, in turn, enhance performance. In fact, she established that 'the rigor and discipline of Six Sigma can be leveraged for measuring and improving performance' (p. 501).

Another case study, conducted by Kumar et al. (2016) showed that the DMAIC approach improved the performance of an ideal retail supply chain model, since it helped the organisation identify and solve problems by determining the root causes of poor performance. Additionally, the use of FMEA and Monte Carlos Simulation tools 
helped monitor the process to ensure sustainability of improvements and optimize its performance.

Thus, the authors propose:

Proposition 1a: The Six Sigma structured approach provides standards, systems and roadmaps that help to improve the efficiency and control of processes, products and services, enhancing exploitation orientation.

Another Six Sigma practice is the particular set of statistical metrics. Six Sigma offers some complex quantitative metrics such as DPMO, RTY, CTQ, defects measures, and 10x improvement measures in order to stabilise, improve and control quality processes, products, services and projects as well as to reduce the variance in the processes leading to zero defects (exploitation orientation). They also help to identify and allocate resources efficiently (exploitation orientation) (Breyfogle et al, 2001; Linderman et al, 2003; Mehrjerdi, 2011; Nikolac et al, 2015; Kuvvetli et al, 2016).

The main goal of QM is to fulfil customer satisfaction. To this end, Six Sigma metrics may help organisations understand and collect information about customers' needs and, then improve the fit and design of their processes, projects, products and services (exploitation orientation). Furthermore, they also help to collect quality information about manufacturing processes in order to solve operational problems (exploitation orientation) (Henderson et al, 2000; Antony, 2004; Aggogery et al, 2008; Mehrjerdi, 2011).

Furthermore, the continued use of these metrics fosters the exchange of information concerning manufacturing processes and procedures as well as the development of explicit knowledge and learning between workers. This information exchange, as well as learning and knowledge creation, enable the creation of common languages and a shared vision within organisations, leading to successful 'embeddedness' of a quality strategy, in addition to identifying and removing implementation barriers. They also help to reduce the waiting time in processes and solve problems related to manufacturing processes, projects, products and services, resulting in speeding up procedures and processes (exploitation orientation) (Linderman et al, 2004; Van Barnevelds et al, 2012; Zeng et al, 2013; Gutierrez-Gutierrez et al, 2016b) (refer to fig. 1). For example, Moosa and Sajid (2010) carried out a study using multiple case studies. 
The authors argued that metrics such as DPU and DPMO are useful for comparing two different products and their processes. Thus, both products and processes can be compared to improve their efficiency. Additionally, a similar case study, in the construction sector, showed the impact of another Six Sigma metric, such as CTQ, to improve the efficiency of processes and procedures to set a definite goal for improvements, and reduce the processes variability and minimise wastes (Heon Han et al, 2008).

According to the arguments explained above, the authors establish the following proposition:

Proposition 1b: Six Sigma metrics help to identify implementation barriers, reduce waiting time, solve different issues and speed up processes and procedures improving their efficiency and enhancing exploitation orientation.

Finally, the Six Sigma role structure promotes boundary-spanning activities in order to explore problems and, in turn, helps organisations control processes and procedures (exploitation orientation) within organisations, as it provides a methodological framework to guide specialists (Zhang et al, 2012; MahourMellat, 2014; He et al, 2015; Gutierrez-Gutierrez et al, 2016a). Moreover, the Six Sigma reward systems along with its hierarchical coordination mechanism of work, where leaders support and review key improvement projects, enables organisations to allocate resources and identify and remove barriers in order to achieve better control, improvement and design of quality processes, procedures, projects, products and services (Linderman et al, 2003; Choo et al, 2007; Schroeder et al, 2008) (refer to fig. 2). For example, Zhang et al. (2015) carried out a study case at the world's largest cold rolling mill in China, called 'company $\mathrm{T}$ '. Company $\mathrm{T}$ designed a career plan to encourage workers involvement in Six Sigma implementation, particularly, Black Belts, Green Belts and Yellow Belts, as Six Sigma will never succeed without their active participation. Furthermore, it offered a monetary reward based on the hard saving of the successful project they finished. On the other hand, company T offered training to workers related to Six Sigma and they are required to utilise what they learned in the classroom for their projects with the help of consultants. The engineers of company T concluded that the use of Six Sigma helped to raise the efficiency and quality management level within the organization, elevating operational efficiency of equipment and facilitating on-time production. 
So, the authors propose:

Proposition 1c: Six Sigma role structure provides a methodological framework to guide specialists to improve the efficiency and control of processes and procedures and to identify implementation barriers and allocate resources, enhancing exploitation orientation.

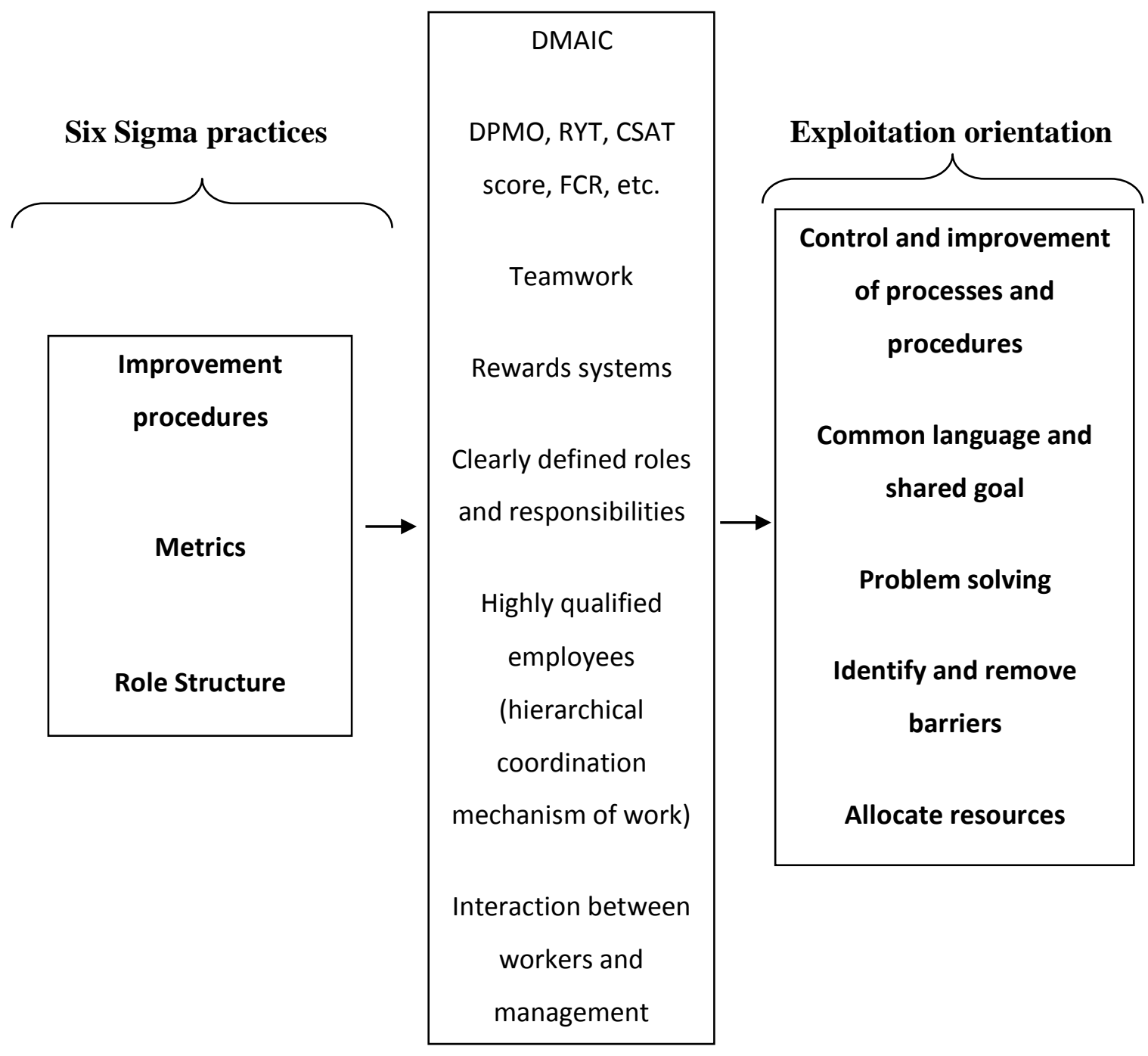

Source: Own elaboration

Figure 2. Influence of Six Sigma on exploitation orientation

\subsection{Six Sigma and exploration orientation}

Scholars have developed a new Six Sigma approach focused on designing and redesigning processes, procedures, projects, products and services, which is directly related to innovation (exploration orientation). It is called DMADV or Design for Six Sigma (DFSS) (Shahin, 2008; Azis \& Osada, 2010; Gremyr \& Fouquet, 2012; 
Kumaravadivel et al, 2013; He et al, 2015). According to Azis and Osada (2010), this approach allows for radical innovation by designing new processes, products or services based on customer needs and expectations. It offers an opportunity to learn from mistakes, as it helps organisations identify gaps in their processes, products or services throught an internal and external analysis of their position (Kim et al, 2012; Zu et al, 2008). For instance, the use of tools such as benchmarking and SWOT in the first three steps ('Define', 'Measure' and 'Analysis'), can help to identify new potential business models, since organisations may compare their processes, products and services with other leaders and innovators in the marketplace. Additionally, information collected and ideas shared during the development of DMADV phases may encourage creativity and, in turn, create new knowledge and ideas to design the production and innovative processes (exploration orientation). Moreover, tools such as conjoint analysis, design of experiments and quality function deployment needed to develop candidate concept design and used during the different phases of DMADV, promote innovation within organizations (Montomgery, 2008; Jensen et al., 2012; Li et al., 2013; Hockman and Jensen, 2016). They facilitate the development of process, products or services, since these tools help to define goals, hypotheses and problem statements, clarify the purpose and collect the voice of the customer, providing tactics thinking which encourages the statistician to look beyond the numbers (Tan and Shen, 2000; Goh, 2002; Lee et al., 2008; K. Narasimhan, 2009; Hoerl and Snee, 2010; Li et al., 2013). Therefore, organisations may promote exploratory orientation by means of this approach and tools, since they foster the search, discovery, novelty and innovation to achieve innovative processes, projects, products and services in order to meet customer expectations and, in turn, generate new solutions and ideas (exploration orientation) (refer to fig. 2). For example, a case study developed by Bañuelas and Antony (2004) described the different steps of DMADV in a company called 'A'. At first, its goal was to improve the process of identifying, quantifying and eliminating the source of variation that resulted in failure to change from a spindle or roll to another by the re-winder machine. Nevertheless, information collected during the first three phases of DMADV ('Define', 'Measure' and 'Analysis') helped workers realise that it was useless to try to improve processes when their fundamental design was wrong, so they had to redesign them.

On the other hand, Gremyr and Fouquet (2012) conducted a case study of seven organisations (six of them are from Sweden and one is from France). It showed that 
these organisations achieved not only to reduce development costs, to focus on robust development and robust engineering, but also to increase customer focus and product reliability using the DMAIC approach. In fact, one interviewee stated that DMADV or DFSS 'is very good way to design products with customer focus, and to gen robust products'.

So, the authors propose:

Proposition 2a: The Six Sigma DMADV approach promotes the redesign and search of new potential business models, products, services, process and procedures and, in turn, it helps to embed innovation strategy within organisations, enhancing exploration orientation.

Six Sigma provides complex and comprehensive statistical metrics to collect information about customers' needs and competitors, so organisations may foresee customer expectations and know what the competition is doing, which leads to knowledge creation (Antony, 2004; Aggogery et al, 2008; Hoerl \& Gardner, 2010; Sin et al, 2010; Mehrjerdi, 2011; Zahng et al, 2014; He et al, 2015; Gutierrez-Gutierrez, 2016b). Some scholars claim that the main challenge of DMADV is to acquire accurate information about customer needs, so Six Sigma itself provides statistical metrics required to face this challenge, such as DPMO, RTY, CSAT score, CTQ, defects and 10x improvement measures, and so forth.

Furthermore, the knowledge of customers' needs results in increasing the market share as well as a better organisational adaptability to dynamic environments (Raisch et al, 2009). Therefore, Six Sigma metrics help organisations identify potential customers as well as customers' requirements and needs, leading to reliable information to design and redesign new products and services (exploration orientation) (refer to fig. 3). For example, Antony (2015) carried out a case study in a banking call centre using Six Sigma metrics, such as DPMO, CSAT score, CTQ tree, first call resolution \% (FCR) or net promoter score (NSP), in order to measure and know customer satisfaction and expectations, and improve business performance. They showed the importance of Six Sigma implementation and the establishment of right metrics in this type of organisation, since call centres are the first contact point with organisations (Taylor et al, 2003). Furthermore, the large amount of data, which was collected help to understand evolving customer requirements, identifies customer segments and trends in 
customer behaviour. In addition, all of this information can be useful to design and redesign processes, products or services in order to meet customer demands. On the other hand, the engineers and quality management employees of company $\mathrm{T}$, analyzed by Zhang (2015) and described above, claimed that making good use of data in Six Sigma implementation helps to achieve quality management innovation.

Thus, the authors establish the following proposition:

Proposition 2b: Six Sigma metrics help to foresee customers' expectations and identify potential customers through the collection of quality information, contributing to redesigning processes, products or services in order to meet customer demand, enhancing exploration orientation.

Some researchers point out teamwork as the key factor for Six Sigma success, because team members are the main carriers of Six Sigma methodology (Banuelas \& Antony, 2002; Gutierrez et al, 2012). Furthermore, the group of improvement specialists, who receive intensive training, supports and encourages other workers to come up with new ideas for projects, processes, products and services through the use of thinking mechanisms such as brainstorming, group problem-solving or group meetings. They also foster learning and knowledge flow between workers and areas within organisations (exploration orientation) (Azis \& Osada, 2010; Pepper \& Spedding, 2010; Sony \& Naik, 2011; Gutierrez, 2012; He et al, 2015; Gutierrez-Gutierrez et al, 2016b; Antony \& Karaminas, 2016). Thus, these activities (workers training and teamwork) promote learning and knowledge creation, since workers learn from each other while developing their tasks. As a result, Six Sigma generates a good working environment where workers can develop their creativity and, in turn, design new and innovative quality processes, projects, products and services (exploration orientation) (refer to fig. 3). For example, as noted above, Zhang et al. (2015) carried out a study case in a Chinese organisation. Six Sigma managers provide not only support and resources to Six Sigma implementation, but also convey innovation culture among workers, particularly, involved in Six Sigma implementation.

Based on the arguments explained in this section, the authors establish the following proposition: 
Proposition 2c: Six Sigma improvement specialists support and encourage other workers to be creative and innovative using mechanisms for thinking (brainstorming, group problem solving, group meetings and so on), enhancing exploration orientation.

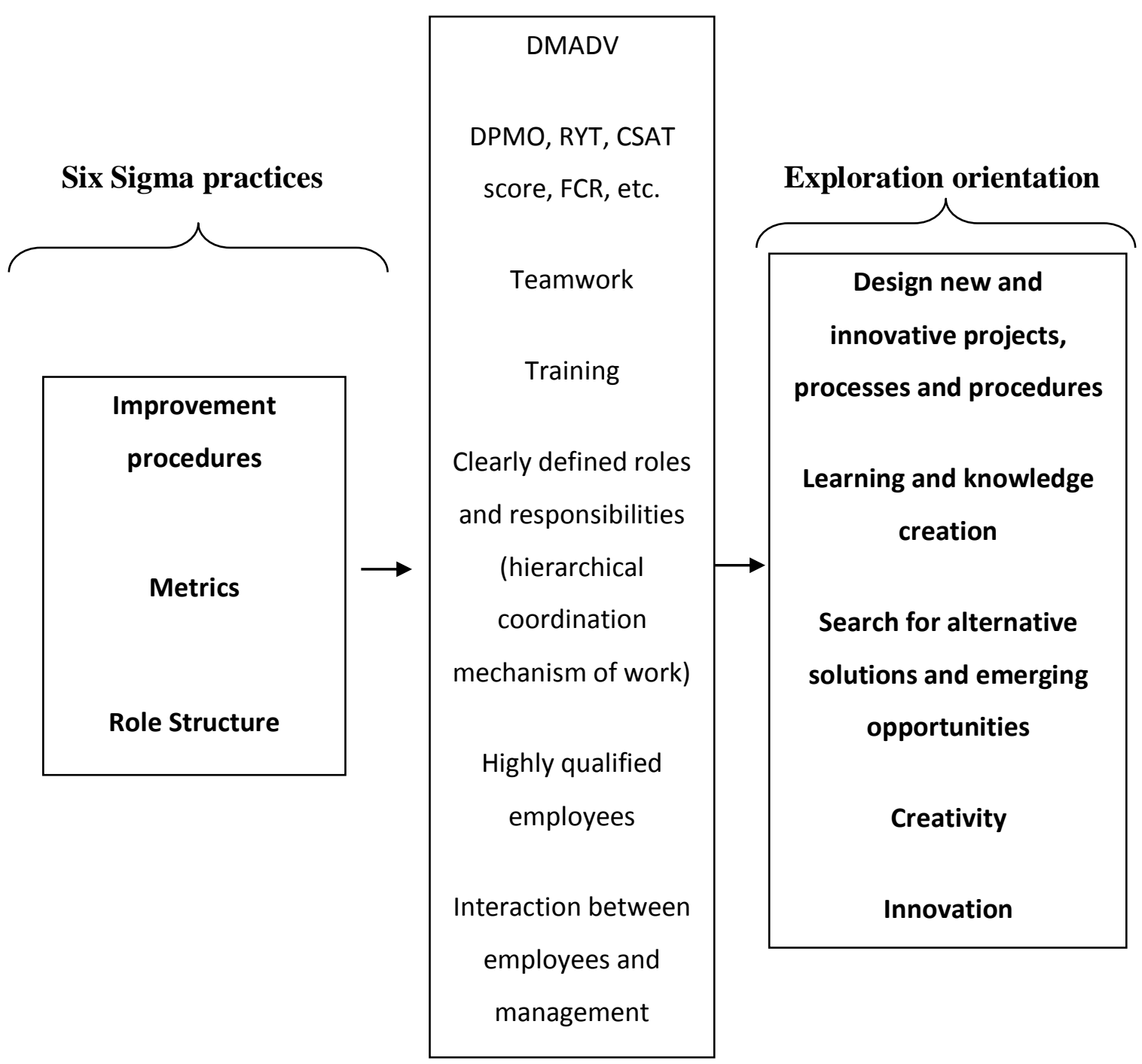

Source: Own elaboration

Figure 3. Influence of Six Sigma on exploration orientation

\subsection{Organisational ambidexterity}

As noted above, developing exploitation orientation may enhance business performance, but it may result in an inability to respond to changing environments (Leonard-Barton, 1992; Ahuja \& Lampert, 2001; Benner \& Tushman, M.L., 2003; Li et 
al, 2008; Lavie et al, 2010). On the other hand, promoting exploration orientation may enhance the ability to renew knowledge and learning within organisations, but it may be a trap for them, since it may lead to an endless cycle of searching for and collecting information (Volberda \& Lewin, 2003). Hence, both orientations should be bolstered, depending on organisational strategies. Following the previous propositions, the authors propose that Six Sigma may help organisations develop both orientations (organisational ambidexterity), and organisations must adequately balance them to be successful. Based on this, the authors propose:

Proposition 3: The Six Sigma structure promotes activities relating to the efficiency and control of processes, products and services (exploitation orientation) as well as those activities that foster innovation and creativity in processes, products and services (exploration orientation), developing ambidexterity.

Based on the above propositions, the authors propose a research model that shows the relationship between Six Sigma practices and ambidexterity (refer to fig. 4).

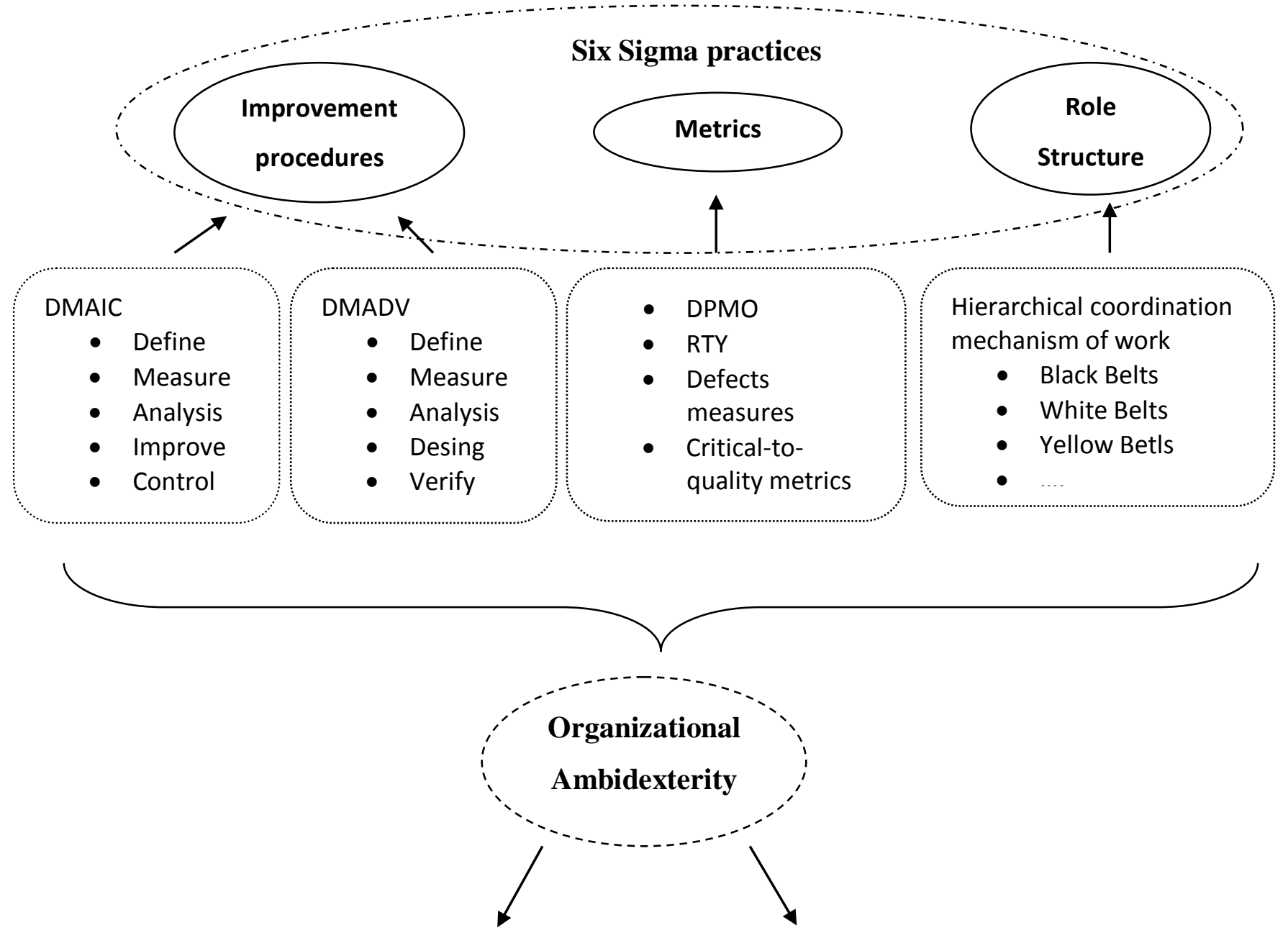




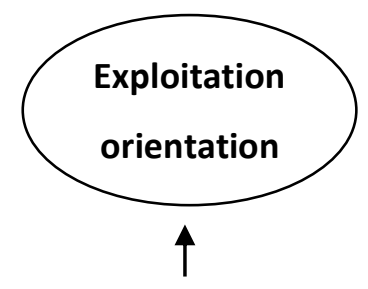

- Customer input

- Improvement of process and procedures

- Control of processes and procedures

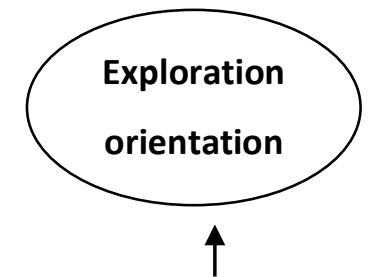

- Innovation

- Creativity

- Discovery

- Experimentation

- Exploration of new alternatives

Source: Own elaboration

Figure 4. Research model

\section{Conclusions and directions for further research}

Because of many studies showing the benefits of Six Sigma, both academics and practitioners are paying increasing attention to this quality management methodology. Scholars have shown that as Six Sigma promotes the development of distinctive competencies such as flexibility, fast delivery, rapid design or redesign, low cost, and so on, which affect organisational performance (Gutierrez et al, 2012, Pepper et al, 2010; Easton \& Rosenzweig, 2012; Reosekar et al, 2014). Likewise, it emphasises the importance of cross-functional design, customer input, design for manufacturability, design projects, robust design and quality function deployment focused on meeting customers' expectations (Hoerl, 2001; Rowlands, 2003; Hoerl et al, 2010; Choi, 2012). Thus, Six Sigma helps organisations achieve a competitive position in the marketplace.

Despite efforts to understand Six Sigma methodology, so far, no consensus has been reached on why some organisations have adopted Six Sigma successfully while others do not. There are mixed results; hence, this study provides new insights to achieve a greater understanding of Six Sigma and to identify how Six Sigma bolsters exploration and exploitation orientations.

After carrying out a deep and systematic literature review about Six Sigma and ambidexterity, the authors concluded that Six Sigma is positively related to 
organisational ambidexterity. Six Sigma helps organisations develop exploitation activities, because its particular role structure in combination with its hierarchical coordination mechanism of work, quantitative metrics and DMAIC approach guide workers to develop different tasks, solve problems, develop, improve and optimise the efficiency and control of processes, products and services. Furthermore, these practices facilitate the interaction between different members and departments within organisations, generating a common language and shared vision and, in turn, enable the identification and removal of implementation barriers as well as the allocation and identification of resources. Moreover, Six Sigma also promotes exploration activities, since the DMADV approach and the use of quantitative metrics offer the opportunity to learn from mistakes and, in turn, help to translate the voice of the customer into the business and engineering language, identifying trends in the marketplace. In addition, its particular role structure promotes teamwork, learning and knowledge creation as well as the interaction between workers and areas, which leads to a creative environment and innovation culture in order to design and redesign innovative processes, projects, products and services (Schroeder et al, 2008; Zu et al, 2010; Azis \& Osada, 2010; Kumaravadivel et al, 2013; Mahour Mellat, 2014; He et al, 2015; Gutierrez-Gutierrez et al, 2016b). Therefore, Six Sigma fosters the development of organisational ambidexterity.

Our study aims to convey a sense of how Six Sigma can influence and help organisations promote organisational ambidexterity, by analysing Six Sigma literature and its strengths and weaknesses. Moreover, future research can test the theory proposed here. This will require an empirical analysis that validates the propositions and theories provided about Six Sigma and ambidexterity. This theory testing should extend our scientific knowledge concerning Six Sigma and ambidexterity, and verify or refute certain key elements of the theory developed here. Therefore, the authors hope that our initial effort will provide a beginning for future scientific research and a better understanding of this important philosophy.

On the other hand, at present, there is an emerging discussion on whether organisations must combine exploration and exploitation orientations (organisational ambidexterity) or, in contrast, they only focus on one of them-that is, carrying out exploration orientation regardless of exploitation orientation or vice versa. The authors believe that both phenomena might be related to each other; in other words, might the failure of Six 
Sigma be explained by developing the wrong combination of both orientations? It would be interesting to analyse this relationship for future research and also examine which type of combination would be the most appropriate in order to achieve a competitive advantage.

Regarding limitations, the main limitations of a literature review are the complete reliance on previously published research and the availability of thesis studies using the method outlined in the search methodology; in addition to the appropriateness of this research with the criteria of the inclusion/exclusion procedure.

Furthermore, this conceptual analysis has important implications for academics, practitioners and employers, as it provides new theoretical insights to the scarce literature that studies the relationship between QM practices and organisational ambidexterity. The authors provide a better understanding of Six Sigma philosophy as well as some fresh, new insights on how Six Sigma practices may help organisations develop distinctive competitive competencies by its influence over exploration and exploitation orientations (ambidexterity). Therefore, it might be of interest to practitioners who are interested in achieving a successful competitive position and discovering emerging business opportunities, as it may provide some guidance on the important implications of Six Sigma practices over exploration and exploitation orientations.

\section{References}

Aggogeri, F., and Gentili, E. (2008). "Six Sigma methodology: An effective tool for quality management", International Journal of Manufacturing Technology and Management, Vol. 14 No. 3-4, pp. 289-298.

Ahuja, G. and Morris Lampert, C. (2001). "Entrepreneurship in the large corporation: A longitudinal study of how established firms create breakthrough inventions", Strategic Management Journal, Vol. 22, No. 6-7, pp. 521-543.

Alavi, M.J., Chair L.C., (2001). "Review: Knowledge management and knowledge management systems: conceptual foundation and research issues”, MIS Quarterly, Vol. 25 No. 1, pp. 107-130. 
Alcaide-Muñoz, L. and Rodríguez Bolívar, M. P. (2015). “Understanding e-government research: A perspective from the information and library science field of knowledge”, Internet Research, Vol. 25 No. 4, pp. 633-673.

Anand, G., Ward, P.T., Tatikonda, M.V., (2010). "Role of explicit and tacit knowledge in Six Sigma projects: An empirical examination of differential project success", Journal of Operations Management, Vol. 28 No. 4, pp. 303-315.

Antony, J. (2015). "Six-sigma for improving Top-Box Customer Satisfaction score for a banking call centre". Production Planning \& Control, Vol. 26 No. 6, pp. 12911305.

Antony, J., and Karaminas, H. (2016). "Critical assessment on the Six Sigma Black Belt roles/responsibilities, skills and training: A global empirical study”. International Journal of Quality \& Reliability Management, Vol. 33 No. 5, pp. 558-573.

Antony, J. (2004). "Some pros and cons of six Sigma: an academic perspective", The TQM Magazine, Vol. 16 No. 4, pp. 303-306.

Arumugam, V., Antony, J., and Linderman, K. (2016). "The influence of challenging goals and structured method on Six Sigma project performance: A mediated moderation analysis", European Journal of Operational Research, Vol. 254 No. 1, pp. 202-213

Arumugam, V., Antony, J., and Kumar, M. (2013). "Linking learning and knowledge creation to project success in Six Sigma projects: An empirical investigation", International Journal of Production Economics, Vol. 141 No. 1, pp. 388-402.

Azis, Y., and Osada, H. (2010). "Innovation in management system by Six Sigma: an empirical study of world-class companies", International Journal of Lean Six Sigma, Vol. 1 No. 3, pp. 172-190.

Banuelas Coronado, R. and Antony, J. (2002). "Critical success factors for the successful implementation of six Sigma projects in organisations", The TQM magazine, Vol. 14 No. 2, pp. 92-99.

Bañuelas, R., and Antony, J. (2004). "Six sigma or design for six sigma?". The TQM magazine, Vol. 16 No. 4, pp. 250-263.

Barney, M. F. (2002). "Macro, Meso, Micro: Six Sigma”, The Industrial Organizational Psychologist Vol. 39 No. 4, pp. 104-107.

Benner, M.J., Tushman, M.L., (2003). "Exploitation, exploration, and process management: The productivity dilemma revisited", The Academy of Management Review, Vol. 28 No. 2, pp. 238-256. 
Birkinshaw, J., and Gibson, C. (2004). "Building ambidexterity into an organization", MIT Sloan Management Review, Vol. 45 No. 4, p. 47.

Breyfogle III, F. W. and Meadows, B. (2001). "Bottom-line success with Six Sigma". Quality Progress, Vol. 34 No. 5, p. 101.

Buch, K., \& Tolentino, A. (2006). "Employee perceptions of the rewards associated with six sigma”. Journal of Organizational Change Management, Vol. 19 No. 3, pp. 356-364.

Buch, K., \& Rivers, D. (2001). "TQM: the role of leadership and culture". Leadership \& Organization Development Journal, Vol. 22 No. 8, pp. 365-371.

Cardinal, L.B., Sitkin, S.B., Long, C.P., (2004). "Balancing and rebalancing in the creation and evolution of organizational control", Organization Science, Vol. 15 No. 4, pp. 411-4310.

Choi, B., Kim, J., Leem, B., Lee, C., Hong, H., (2012). "Empirical analysis of the relationship between Six Sigma management activities and corporate competitiveness", International Journal of Operations and Production Management Vol. 32 No. 5, pp. 528-550.

Chakravorty, S. S. (2009). "Six Sigma failures: An escalation model”, Operations management research, Vol. 2 No. 1-4, pp. 44-55.

Chandrasekaran, A., Linderman, K. and Schroeder, R. (2012). "Antecedents to ambidexterity competency in high technology organizations", Journal of Operations Management, Vol. 30 No. 1, pp. 134-151.

Choo, A.S., Linderman, K.W. and Schroeder, R.G., (2007). "Method and context perspectives on learning and knowledge creation in quality management", Journal of Operations Management, Vol. 25, pp. 918-931.

De Mast, J. and Lokkerbol, J. (2012). "An analysis of the Six Sigma DMAIC method from the perspective of problem solving”, International Journal of Production Economics, Vol. 139 No. 2, pp. 604-614.

Denyer, D. and Tranfield, D. (2009). Producing a systematic review.

Easton, G.S. and Rosenzweig, E.D., (2012). "The role of experience in Six Sigma project success: An empirical analysis of improvement project", Journal of Operations, Vol. 30 No. 7-8, pp. 481-493.

Eriksson, E., (2013). "Exploration and exploitation in project-based organizations: Development and diffusion of knowledge at different organizational levels in 
construction companies”, International Journal of Project Management, Vol. 31, pp. 333-341.

Foster Jr, S. T. (2007). "Does Six Sigma Improve Performance?”, The Quality Management Journal, Vol. 14 No. 4, p. 7.

Gibson, C. B., and Birkinshaw, J. (2004). "The antecedents, consequences, and mediating role of organizational ambidexterity". Academy of management Journal, Vol. 47 No. 2, pp. 209-226.

Goh, T. N. (2002). "The role of statistical design of experiments in six sigma: perspectives of a practitioner". Quality Engineering, Vol. 14 No. 4, pp. 659-671.

Gremyr, I., and Fouquet, J. B. (2012). "Design for Six Sigma and lean product development”, International Journal of Lean Six Sigma, Vol. 3 No. 1, pp. 45-58.

Gupta, P. (2005). "The Six Sigma performance handbook: a statistical guide to optimizing results". McGraw Hill Professional.

Gutiérrez, L.J.; Bustinza, O.F.; Barales, V., (2012). "Six Sigma, absorptive capacity and organizational learning orientation", International Journal of Production research, Vol. 50 No. 3, pp. 661-675.

Gutierrez-Gutierrez, L.J., De Leeuw, S. and Dubbers, R. (2016a): "Logistics services and Lean Six Sigma implementation: a case study". International Journal of Lean Six Sigma. Forthcoming. Vol. 7 No. 3.

Gutierrez-Gutierrez, L. J.; Barrales Molina, V. and Tamayo Torres, J. (2016b): "The knowledge transfer process in Six Sigma subsidiary firms", Total Quality Management \& Business Excellence. Vol. 27, No. 5-6, pp. 613-627.

Gupta, A. K., Smith, K. G. and Shalley, C. E. (2006). "The interplay between exploration and exploitation", Academy of management journal, Vol. 49 No. 4, pp. 693-706.

Hahn, G. J., Doganaksoy, N. and Hoerl, R. (2000). "The evolution of six Sigma", Quality Engineering, Vol. 12 No. 3, pp. 317-326.

Hartley, J. and Kostoff, R. N. (2003). "How useful are "Key Words" in Scientific Journals?”, Journal of Information Science, Vol. 29 No. 5, pp. 433-438

Harry, M. J. (1998). "Six Sigma: a breakthrough strategy for profitability”, Quality progress, Vol. 31 No. 5, p. 60.

He, Z.; Deng, Y.; Zhang, M.; Zu, X. and Antony, J. (2015). “An empirical investigation of the relationship between Six Sigma practices and organizational innovation”, Total Quality Management and Business Excellence, pp. 1-22. 
He, Z. L. and Wong, P. K. (2004). "Exploration vs. exploitation: An empirical test of the ambidexterity hypothesis", Organization science, Vol. 15 No. 4, pp. 481-494.

Henderson, K. M. and Evans, J. R. (2000). Successful implementation of Six Sigma: benchmarking General Electric Company. Benchmarking: An International Journal, Vol. 7 No. 4, pp. 260-282.

Hockman, K. K., \& Jensen, W. A. (2016). "Statisticians as innovation leaders". Quality Engineering, Vol. 28 No. 2, pp.165-174.

Hoerl, R. W., Montgomery, D. C., Lawson, C., \& Molnau, W. E. (2001). "Six Sigma black belts: What do they need to know?/Discussion/Response". Journal of Quality Technology, Vol. 33 No. 4, p. 391.

Hoerl, R. W., and Gardner, M. M. (2010). "Lean Six Sigma, creativity, and innovation”, International Journal of Lean Six Sigma, Vol. 1 No. 1, pp. 30-38.

Hoerl, R. W., \& Snee, R. (2010). "Statistical thinking and methods in quality improvement: a look to the future". Quality engineering, Vol. 22 No. 3, pp. 119129.

Im, G. and Rai, A. (2008). "Knowledge sharing ambidexterity in long-term interorganizational relationships”, Management Science, Vol. 54 No. 7, pp. 1281 1296.

Jensen, W., Anderson-Cook, C., Costello, J. A., Doganaksoy, N., Hoerl, R. W., Janis, S., \& Snee, R. D. (2012). "Statistics to Facilitate Innovation*: A Panel Discussion". Quality Engineering, 24(1), 2-19.

Jing Sheng, Zhen He, Xing Shi, (2002) "Integration of Design of Experiments into Quality Function Deployment", Asian Journal on Quality, Vol. 3 Iss: 1, pp.71 - 84

K. Narasimhan, (2009) "Voice of the Customer: Capture and Analysis", The TQM Journal, Vol. 21 Iss: 6, pp.636 - 637

Kortmann, S. (2015). “The Mediating Role of Strategic Orientations on the Relationship between Ambidexterity-Oriented Decisions and Innovative Ambidexterity", Journal of Product Innovation Management, Vol. 32 No. 5, pp. 666-684.

Kriebel, L. and Lapham, L. (2008). "Transition to electronic resources in undergraduate social science research: A study of honors theses bibliographies, 1999-2005”, College \& Research Libraries, Vol. 69 No. 3, pp. 268-284.

Kristal, M.M., Huang, X., Roth, A.V., (2010). "The effect of an ambidextrous supply chain strategy on combinative competitive capabilities and business performance", Journal of Operations Management Vol. 28 No. 5, pp. 415-429. 
Kumar, S., Tiffany, M., \& Vaidya, S. (2016). "Supply chain analysis of e-tailing versus retailing operation-a case study". Enterprise Information Systems, Vol. 10 No. 6, pp. 639-665.

Kumaravadivel, A. and Natarajan, U. (2013). “Application of Six-Sigma DMAIC methodology to sand-casting process with response surface methodology", The International Journal of Advanced Manufacturing Technology, Vol. 69 No. 5-8, pp. 1403-1420.

Kuvvetli, Ü., Firuzan, A. R., Alpaykut, S., \& Gerger, A. (2016). "Determining Six Sigma success factors in Turkey by using structural equation modeling". Journal of Applied Statistics, Vol. 43 No. 4, pp. 738-753.

Lan, Z. and Anders, K. K. (2000). "A paradigmatic view of contemporary public administration research: an empirical test", Administration and Society, Vol. 32 No. 2, pp. 138-165.

Lavie, D., Stettner, U., and Tushman, M. L. (2010). "Exploration and exploitation within and across organization”, The Academy of Management Annals, Vol. 4 No. 1, pp. 109-155.

Legge, J.S. Jr., and Devore, J. (1987). "Measuring productivity in U.S. public administration and public affairs programs 1981-1985”, Administration and Society, Vol. 19 No. 2, pp. 147-156.

Leonard-Barton, D. (1992). "Core capabilities and core rigidities: A paradox in managing new product development”, Strategic management journal, Vol. 13 No. 1, pp. 111-125.

Li, Y., Vanhaverbeke, W., and Schoenmakers, W. (2008). "Exploration and exploitation in innovation: Reframing the interpretation", Creativity and innovation management, Vol. 17 No. 2, pp. 107-126.

Li, W., C. J. Nachtsheim, K. Wang, R. Reul, and M. Albrecht. (2013). "Conjoint analysis and discrete choice experiments for quality improvement". Journal of Quality Technology, Vol. 45 No. 1, pp. 74-99.

Linderman, K., Schroeder, R.G., Zaheer, S., Liedtke, C., Choo, A.S., (2004). "Integrating quality management practices with knowledge creation processes", Journal of Operations Management, Vol. 22 No. 6, pp. 589-607.

Linderman, K., Schroeder, R.G., Choo, A.S., (2006). "Six Sigma: The role of goals in improvement teams", Journal of Operations Management, Vol. 24 No. 6, pp. 779790. 
Lee, Y. C., Sheu, L. C., \& Tsou, Y. G. (2008). "Quality function deployment implementation based on Fuzzy Kano model: An application in PLM system". Computers \& Industrial Engineering, Vo. 55 No. 1, pp. 48-63.

Levinthal, D. A. and March, J. G. (1993). "The myopia of learning". Strategic management journal, Vol. 14 No. 2, pp. 95-112.

McAdam, R., Antony, J., Kumar, M., and Hazlett, S. A. (2014). “Absorbing new knowledge in small and medium-sized enterprises: A multiple case analysis of Six Sigma”, International Small Business Journal, Vol. 32 No. 1, pp. 81-109.

Mahour Mellat, P., (2011). "The effect of Six Sigma projects on innovation and firm performance", International Journal of Project Management, Vol. 29, pp. 45-55.

March, J. G. (1991). "Exploration and exploitation in organizational learning", Organization science, Vol. 2 No. 1, pp. 71-87.

Mehrjerdi, Y.Z. (2011), "Six-Sigma: methodology, tools and its future”, International Journal of Assembly Automation, Vol. 31 No. 1, pp. 79-88.

Montgomery, D. C., and W. H. Woodall. (2008). "An overview of Six Sigma". International Statistical Review, Vol. 76 No. 3, pp. 329-346.

Moosa, K., \& Sajid, A. (2010). “Critical analysis of Six Sigma implementation”. Total Quality Management, Vol. 21 No. 7, pp. 745-759.

Moreno Luzon, M. D. and Valls Pasola, J. (2011). “Ambidexterity and total quality management: towards a research agenda". Management Decision, Vol. 49 No. 6, pp. 927-947.

Nair, A., Malhotra, M.K., Ahire, S.L., (2011). "Toward a theory of managing context in Six Sigma process-improvement projects: An action research investigation", Journal of Operations Management, Vol. 29, pp. 529-548.

Newbert, S. L. (2007). "Empirical research on the resource-based view of the firm: an assessment and suggestions for future research", Strategic Management Journal, Vol. 28 No. 2, pp. 121-146.

Nikolac, N., Panteghini, M., Theodorsson, E., Salvagno, G. L., Miler, M., Simundic, A. M., and Westgard, S. (2015). "How to assess the quality of your analytical method?". Clinical Chemistry and Laboratory Medicine (CCLM), Vol. 53 No. 11, pp. 1707-1718.

Nord, J. H. and Nord, G. D. (1995). "MIS research: Journal status and analysis", Information and Management, Vol. 29 No. 1, pp. 29-42 
O'Connor, G. C., and DeMartino, R. (2006). "Organizing for radical innovation: An exploratory study of the structural aspects of RI management systems in large established firms", Journal of product innovation management, Vol. 23 No. 6, pp. 475-497.

O’Reilly, C. A., and Tushman, M. L. (2008). “Ambidexterity as a dynamic capability: Resolving the innovator's dilemma", Research in organizational behavior, Vol. 28, pp. 185-206.

Prashar, A. (2016). "Six Sigma adoption in public utilities: a case study". Total Quality Management \& Business Excellence, Vol. 27 No. 5-6, pp. 479-506.

Pepper, M. P. J., and Spedding, T. A. (2010). "The evolution of lean Six Sigma", International Journal of Quality and Reliability Management, Vol. 27 No. 2, pp. $138-155$.

Prieto, I. M., and Pilar Pérez Santana, M. (2012). "Building ambidexterity: The role of human resource practices in the performance of firms from Spain", Human Resource Management, Vol. 51 No. 2, pp. 189-211.

Raisch, S., Birkinshaw, J., Probst, G. and Tushman, M. L. (2009). "Organizational ambidexterity: Balancing exploitation and exploration for sustained performance”, Organization science, Vol. 20 No. 4, pp. 685-695.

Rodríguez Bolívar, M.P., Alcaide Muñoz, L., and López Hernández, A.M. (2010). "Trends of e-Government Research. Contextualization and Research Opportunities", The International Journal of Digital Accounting Research. Vol. 10, pp. 87-111.

S. Reosekar, R., and D. Pohekar, S. (2014). "Six Sigma methodology: a structured review”, International Journal of Lean Six Sigma, Vol. 5 No. 4, pp. 392-422.

Salvador, F., Chandrasekaran, A., and Sohail, T. (2014). "Product configuration, ambidexterity and firm performance in the context of industrial equipment manufacturing”, Journal of Operations Management, Vol. 32 No. 4, pp. 138-153.

Schroeder, R.G., Linderman, K., Liedtke, C., Choo, A.S., (2008). "Six Sigma: Definition and underlying theory". Journal of Operations Management, Vol. 26, pp. 536-554.

Senapati, N.R. (2004), "Six Sigma: myths and realities", International Journal of Quality \& Reliability Management, Vol. 21 No. 6, pp. 683-690. 
Shahin, A. (2008). "Design for Six Sigma (DFSS): lessons learned from world-class companies", International Journal of Six Sigma and Competitive Advantage, Vol. 4 No. 1, pp. 48-59.

Sin, A. B., Zailani, S., Iranmanesh, M., and Ramayah, T. (2015). "Structural equation modelling on knowledge creation in Six Sigma DMAIC project and its impact on organizational performance” International Journal of Production Economics, Vol. 168, pp. 105-117.

Sin, A. B., Zailani, S., \& Ramayah, T. (2010). "Six Sigma and organisational performance: A knowledge creation perspective". International Journal of Productivity and Quality Management, Vol. 6 No. 2, pp. 182-212.

Sinha, K. K. and Van de Ven, A. H. (2005). "Designing work within and between organizations", Organization Science, Vol. 16 No. 4, pp. 389-408.

Snee, R. D. (2010). "Lean Six Sigma-getting better all the time", International Journal of Lean Six Sigma, Vol. 1 No. 1, pp. 9-29.

Sony, M and Naik, S. (2011). "Six Sigma, organizational learning and innovation. An integration and empirical examination", International Journal of Quality and Reliability Management, Vol. 29 No. 8, pp. 915-936.

Swink, M., Jacobs, B.W., (2012). "Six Sigma adoption: Operations performance impacts and contextual drivers of success", Journal of Operations Management, Vol. 30 No. 6, pp. 437-453.

Tan, K. C., \& Shen, X. X. (2000). "Integrating Kano's model in the planning matrix of quality function deployment”. Total quality management, Vol. 11 No. 8, pp. 1141-1151.Tjahjono, B., Ball, P., Vitanov, V. I., Scorzafave, C., Nogueira, J., Calleja, J. and Yadav, A. (2010). "Six Sigma: a literature review". International Journal of Lean Six Sigma, Vol. 1 No. 3, pp. 216-233.

Tallon, P. P., and Pinsonneault, A. (2011). "Competing perspectives on the link between strategic information technology alignment and organizational agility: insights from a mediation model”, Mis Quarterly, Vol. 35 No. 2, pp. 463-486.

Ullah, A. S. and Harib, K. H. (2008). "An intelligent method for selecting optimal materials and its application", Advanced Engineering Informatics, Vol. 22 No. 4, pp. 473-483.

Van Barneveld, A., Arnold, K. E. and Campbell, J. P. (2012). "Analytics in higher education: Establishing a common language", EDUCAUSE learning initiative, Vol. 1, pp. 1-11. 
Volberda, H. W. and Lewin, A. Y. (2003). "Co-evolutionary dynamics within and between firms: From evolution to co-evolution", Journal of management studies, Vol. 40 No. 8, pp. 2111-2136.

Volery, T., Mueller, S. and von Siemens, B. (2015). "Entrepreneur ambidexterity: A study of entrepreneur behaviours and competencies in growth-oriented small and medium-sized enterprises". International Small Business Journal, Vol. 33 No. 2, pp. 109-129.

Yang, H., Zheng, Y., Zhao, X., (2013). "Exploration or exploitation? Small firms' alliance strategies with large firms", Strategic Management Journal, Vol. 2, pp. 201-221.

Zeng, J., Chi Anh, P. and Matsui, Y. (2013). "Shop-floor communication and process management for quality performance: An empirical analysis of quality management”, Management Research Review, Vol. 36 No. 5, pp. 454-477.

Zhang, J. A., Edgar, F., Geare, A. and O'Kane, C. (2016). "The interactive effects of entrepreneurial orientation and capability-based HRM on firm performance: The mediating role of innovation ambidexterity”. Industrial Marketing Management.

Zhang, M., Wang, W., Goh, T. N., \& He, Z. (2015). “Comprehensive Six Sigma application: a case study”. Production Planning \& Control, Vol. 26 No. 3, pp. 219-234.

Zhang, D., Linderman, K., Schroeder, R.G., (2012). "The moderating role of contextual factors on quality management practices", Journal of Operations Management Vol. 30 No. 1-2, pp. 12-23.

Zu, X., Fredendall, L.D., Douglas, T.J., (2008). "The evolving theory of quality management: the role of Six Sigma”, Journal of Operations Management, Vol. 26, pp. 630-650.

Zu, X., Robbins, T. L. and Fredendall, L. D. (2010). "Mapping the critical links between organizational culture and TQM/Six Sigma practices". International journal of production economics, Vol. 123 No. 1, pp. 86-106. 